\title{
Mundo tradicional y convalecencia metafísica
}

\author{
Jorge Ignacio Ibarra Ibarra \\ Universidad Autónoma de Nuevo León
}

\section{Resumen}

La tradición tiene un amplio abordaje en la filosofía; en la definición de Aristóteles, por ejemplo, es reconocida como fuente de explicaciones cosmológicas y éticas. La edad media la identifica con la autoridad divina. El presente trabajo busca explorar la cuestión de la tradición, no solamente desde su genealogía histórica, sino vista como un conjunto de prácticas sociales y maneras de entender el mundo que sobreviven en un entorno complejo de tensión entre el laicismo y la vuelta del fundamentalismo religioso.

Palabras clave: convalecencia, retorno, pensamiento, débil, Vattimo, Heidegger, cultura, autoridad, tradición, rememorar, hermenéutica.

\begin{abstract}
Tradition has a very vast comprehensive approach in Philosophy; for example, in Aristotle definition is recognized as source of cosmological and ethical explanations. In the middle age it was identify as a divine authority. This essay seeks to explore the question about tradition, not only from its historical genealogy perspective but as well from the social practices and ways of understanding a world where there is a set of tension between secular environment and the return of fundamentalism in religion.
\end{abstract}

Key words: Convalescence, Return (comeback), Thought, Weak, Vattimo, Heidegger, Culture, Authority, Remember, Hermeneutics. 
Sería vano pretender que, porque presentimos el final de la metafisica estamos ya fuera de ella. Porque la metafísica incluso superada no desaparece. Regresa transformada y continua dominando como distinción entre el Ser y el Ente, distinción que sigue en vigor.

M. Heidegger

\section{Introducción}

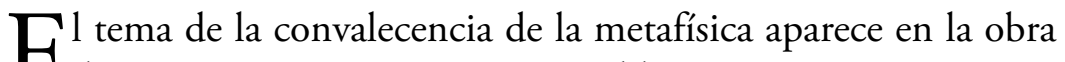
Cde Gianni Vattimo como un problema que se presenta originalmente en los escritos de Heidegger, término que se define como: "los rasgos de una enfermedad que permanecen cuando ésta ha pasado o bien un remitirse a eso pasado como pasado" (Vattimo, 1986: 50). La enfermedad en cuestión según Heidegeer es la Metafísica, y la recuperación con sus secuelas es la convalecencia (Verwindung). En todo caso, completa el italiano, la convalecencia es recordatorio a la vez de una posibilidad. Por nuestra parte, este artículo se referirá a la convalecencia como marco de posibilidad en el cual pueden tomar un nuevo aspecto las prácticas culturales, entre ellas, particularmente, las que se ubican bajo el nombre de tradiciones. Así nuestro tema partirá de un planteamiento metafísico y ontológico para luego colocarse bajo una perspectiva de los terrenos de la filosofía de la cultura, aun cuando el problema aparece en Vattimo referido a la "muerte del arte" como expresión del agotamiento de la metafísica.

La tradición en cuanto objeto de reflexión filosófica es vista desde varias ópticas, ya se le menciona como un tipo de prácticas producto del tiempo histórico en el cual se conforman, o bien (si se considera como una forma de vivir) se destaca en su carácter de formadora de valores y actitudes en los individuos. La caracterización de Heidegger de un mundo dominado por la manipulación 
y el cálculo, en el cual predomina el olvido del Ser y el pensar se manifiesta como ausencia o rememorar (An-deken), remite indirectamente al problema de la tradición, como ritual vacío de contenido y sacralidad, como una de las muchas manifestaciones de la era de la metafísica cumplida (Gestell) que se relaciona con la representación del Ser y el olvido del mismo; dicho de otra manera, las tradiciones, sagradas y no, son prácticas vacías atadas al cálculo racional o político -cuestión que abordaremos más extensamente en lo que sigue-. La convalecencia, por otra parte, será otra manera de considerar el Ser, de pasar de su representación a su experimentación, transición esta última desde la cual buscamos reflexionar sobre la tradición, tanto como objeto abstracto como conjunto de prácticas concretas. En el mundo de la convalecencia, la metafísica tendrá una manera diferente de regresar o darse que implica una nueva manera de vivir y por ello también de valorar. Al seguir cuatro pasos, el presente artículo es una exploración de esta relación:

1. Planteamiento de la superación de la metafísica y convalecencia en la interpretación de Vattimo sobre los conceptos de Heidegger.

2. Ubicación de la tradición como un problema filosófico.

3. Relación de la metafísica con la tradición.

4. La convalecencia y la posibilidad de la tradición como práctica cultural orientada a la diferencia cultural y la vinculación interhumana.

Ahora, paso a tratar el primero de estos pasos ubicando los conceptos de superación y convalecencia en relación con el rememorar. La cuestión es tratada con un marco de consideración a la época del olvido del ser y de lo pensado desde el fundamento. 


\section{Planteamiento: la superación de la metafísica y la convalecencia}

Abordaré el problema de la superación de la metafísica y la convalecencia desde el marco del pensamiento débil de Vattimo, donde ofrece una interpretación de la fenomenología ontológica de Heidegger en sus puntos principales y de los cuales deriva propuestas que atañen, a mi parecer, a la tradición como un fenómeno que se puede asociar a la época del pensamiento del rememorar, donde se sustituye a la metafísica que se inclina a favor de lo ente y el olvido del Ser. El rememorar es entonces aquel pensamiento que supera la metafísica (ueberwindung); sin embargo, tiene que afrontar que no es posible la superación total ya que aquella vuelve (verwindung). De tal manera que la metafísica es aquella época que se ha dejado atrás pero de la cual la humanidad sufre huellas o bien, en el lenguaje de Heidegger, se trata de una convalecencia a la manera de una enfermedad que se ha padecido largo tiempo y de la cual se sale pero manteniendo o sufriendo sus rasgos. El punto de partida es la superación de la metafísica y su correlato de dominación tecnológica y cálculo. El planteamiento viene dado de la siguiente manera por Vattimo:

Es necesario partir del reconocimiento de que en el pensamiento de Heidegger, con respecto a la posibilidad de una superación de la metafísica, presenta una peculiar complejidad, en la cual se oculta quizá también la señal para discutir (y rechazar) de modo más productivo para el pensamiento la hipótesis ahora descripta. Esta complejidad se anuncia en el texto sobre la superación de la metafísica (Ueberwindung der metaphysik) donde la proximidad de los términos superación y convalecencia aluden al hecho de que la metafísica en realidad no se puede superar (1999: 111). 
Es decir que no se le puede dejar de lado como una opinión, pues aun superada vuelve en otra forma afirmando su dominio como permanente distinción del ser respecto de lo que es.

La filosofía de Heidegger indica o invita de esta manera a la aceptación del dominio de la tierra o bien a asumir la técnica, pues en ella se da el envío (Schicken), el darse del ser como un don a lo perceptible sólo para retraerse después. ${ }^{1}$ La invitación a vivir lo dado en el envío, como experiencia de lo ente, se ubica según Vattimo en la orientación del nexo entre superación y convalecencia como una ruta necesaria, una manera de afirmar que no se tiene la superación total sino que ha de vivirse con la metafísica a cuestas. La diferencia ha de venir en la posibilidad de dos tipos de pensamientos: uno de cálculo, que se encuentra totalmente inmerso en el don del ser, y otro que medita, que es reflexivo y adquiere conciencia ya sea de este envío como tal o bien de este darse que conlleva siempre un sustraerse del ser. En la perspectiva de Vattimo, éste parece ser un aspecto productivo pues nos conduce a un pensamiento débil, en el que pasamos a la consideración de un mundo donde sólo es posible concebir la huella del ser, o donde se trata de un aspecto que alimenta una ontología débil donde la caducidad es lo característico. Se ha dicho, por otra parte, que el pensamiento débil propone sólo una actualidad (Berciano, 1993: 14), una época determinada que es la nuestra; no obstante, sin duda, asumo que se ofrece una visión que va más allá de lo estrictamente sociológico e histórico para proponer una forma de pensar la vida y la relación con el Ser dada por la superación de todo pensamiento que busque la representación para ubicarse en su experimentación, propuesta que el mismo Vattimo califica como una lectura de inspiración cristiana en un sentido específico, o bien, cristianismo secularizado.

${ }^{1}$ No se trata, aclara Vattimo, de un Ser desplegado en la existencia, sino el envío como evento permanente, como operación constante entre enviar y retraerse. 
En la interpretación de Vattimo, por otra parte, la convalecencia es la imposibilidad de eliminar la metafísica tal cual. Ya Nietszche anunciaba esta imposibilidad en la voluntad de poder, donde se nos advierte sobre el pesimismo que provoca la revelación de la falsedad de los valores supremos y su supervivencia como meros elementos para juzgar. La posición de Nietszche es continuada críticamente por Heidegger y Vattimo, los cuales localizan esta imposibilidad como resignación y, sin embargo, entrevén una salida en el pensar rememorante. Este rememorar, dice Vattimo:

Piensa al ser como diferencia, como aquello que difiere en muchos sentidos: primeramente, en el sentido de que, en el dar, no se da como tal, y por lo tanto difiere como lo que escapa, que ha estado, y de lo cual la proveniencia, en su porvenir, también siempre se despide; pero también difiere como aquello que es distinto, que en su no reducirse a la apertura abierta la difiere en cuanto que la dis-loca, la suspende en su perentorio carácter de presencia (1996: 121).

La interpretación advierte sobre la confusión de un pensar del pasado ya sea como historia o bien como religioso, pues el rememorar mantiene un aspecto de agradecimiento (Danke) hacia el Ser. Lo cual significa, en el lenguaje de Heidegger, que el pensamiento encuentra en el pensar extático del Ser un pensar y agradecer al mismo tiempo (denken - danken), que a su vez conecta con el pensar como un acontecimiento (anwessenlassen). De esta manera podríamos caracterizar la convalecencia con los siguientes rasgos:

1. Se presenta en relación con la superación de la metafísica o como una contracara de la misma.

2. Se trata de una vivencia débil del Ser que se expresa ya sea en la aceptación de las huellas de la metafísica o bien con una aceptación de la "fábula" o el mundo como apariencia.

3. Mantiene una relación especial con el Ser dada por el rememorar y el agradecer. 
Así, la convalecencia permanece como una nota principal dentro del pensamiento débil a la que habremos de asignar un papel fundamental en la formulación de una nueva época de vivir el ser y hacer filosofía. En este sentido es que Vattimo formula las siguientes preguntas:

¿Se puede verdaderamente esperar que la culminación de la metafísica en la técnica prepare otra época del ser? ¿Puede el pensamiento como rememorar dejar su impronta en una época como ha hecho el pensamiento de la metafísica? ¿O no es constitutivo del rememorar el hecho de no poder volverse principio de una organización de la totalidad del ente, debiendo permanecer siempre, incluso en este sentido, como un viejo topo? (1996: 128-129).

Lo rememorante (andenkend) tiende a persistir en el pensamiento del cálculo oblicuamente y en forma de parodia del mismo para afirmar aquello sin fundamento.

El rememorar es la forma del pensar dada en la convalecencia, su forma particular de vivir ese retraerse del ser o ese carácter ambiguo, pues como seńala Modesto Berciano: "La convalecencia ni piensa el ser como estable ni lo considera como la necesidad lógica de un proceso; ni lo ve como la metafísica, ni como la dialéctica. Por otra parte recupera la tradición metafísica" (1993: 28).

La convalecencia vendrá a ser el tipo de pensar que se identifica con un vivir de manera extática, el ser ahí heideggeriano, una especie de permanente disposición hacia el ser como ausente. ${ }^{2}$ Sin embargo, el pensamiento débil interpreta esta ausencia como ironía, como resignación que no deseamos. Aunque compartimos

${ }^{2}$ La crítica de Berciano a Vattimo en el sentido de que Ueberwimdung no es realmente lo opuesto a Verwindung sino más bien su complemento, pues la superación es de la metafísica lo es desde la metafísica misma se comprende aquí al señalar que una recuperación no es una salida total de la enfermedad sino su vivencia como un estado permanente, la vida con la huella de la enfermedad. O bien, metafísica con la asunción de ser metafísica. 
la aceptación de la ausencia, en definitiva podemos también hacer la lectura del pensamiento débil como una construcción en el sentido de un rememorar que hace acopio de la experiencia del evento (Ereignis) otorgándole una nueva expresión. Aquí es donde podemos apreciar la tradición o las prácticas tradicionales como experiencias culturales y sociales que han de mantener una vinculación con la experiencia primaria del Ser. En suma, las tradiciones tendrían que salir del ámbito cerrado y dogmático de una metafísica, que en términos heideggerianos se encuentra dominada por el cálculo y en el olvido del Ser, para pasar a ser prácticas llenas de agradecimiento con un Ser distante e inalcanzable que, sin embargo, pinta sus huellas en el devenir del tiempo. Aquí, sería conveniente preguntarnos si el religioso (incluso hacer la pregunta para aquellos contextos culturales alejados de la herencia judeocristiana) actúa con virtud o error al negar el rememorar como forma de sustentar sus prácticas tradicionales; puesto que el rememorar, como sabemos, es rechazado o conocido como religiosidad débil o frívola por numerosos grupos fundamentalistas que se rigen por una ortodoxia basada en la letra sagrada o los mandamientos revelados (Gómez Limón, 2011).

\section{La tradición: objeto de reflexión filosófica}

Entonces, la Tradición recorre como un objeto de reflexión distintas etapas que van desde su concepción como depositarias de una verdad absoluta, fundamento del individuo y la sociedad, hasta su imagen como prácticas retrogradas. La revaloración que ha tenido en el siglo XX de la obra generada principalmente por las corrientes fenomenológica y hermenéutica nos tiende un puente hacia la posibilidad como fuente de creatividad y crítica pues, tal como lo señala Teodoro Ramírez, la oposición entre modernidad y tradición resulta cuestionable por ser el tempo de la tradición de 
lo actual e incluso de lo crítico (Ramírez, 2001). Antes de entrar en la posibilidad de la tradición como lugar de actualización o creación, quiero mencionar brevemente la relación entre tradición y metafísica, relación que ha devenido en forma de fundamento trascendente para casi toda la práctica tradicional y se manifiesta en la verdad como autoridad que alegan tener las prácticas tradicionales. Por otra parte, aquellas prácticas que son fundadas en lo lúdico o profano no corresponden a esta fundamentación, pero considero que de alguna manera han tenido o tienen algún tipo de fundamento que les hace ser reconocidas como depositarias del algún tipo de verdad. ${ }^{3}$

Igualmente interesante es el abordaje de la definición de tradición por parte de Alasdair MacIntyre, quien la define como un conjunto de prácticas encarnadas en individuos quienes se encuentran sujetos al pasado que ellas le proporcionan pero que a cambio de tal sujeción ellas proporcionan también el piso de una totalidad o pegamento vital que da coherencia a sus acciones (2001: 273). $\mathrm{Al}$ oponer su punto de vista a la filosofía analítica y existencialista, MacIntyre defiende una vida orgánica y total contra la fragmentación social y humana que ambas filosofías propugnan en su punto de vista. Todos los argumentos de MacIntyre son complejos y bien sustentados como para desarrollarlos en este lugar, no obstante señalaremos como el más sólido aquel que establece la narración como una capacidad humana de dar cuenta de un origen y una finalidad de la existencia (MacIntyre, 2001: 267) capacidad presente de manera natural ${ }^{4}$ sin la cual nos perderíamos en la idiotez y el absurdo. La posición de MacIntyre es inspiradora ya que es uno de los esfuerzos más acabados de nuestro tiempo por esclarecer el problema sobre qué es la tradición y cómo se ubica tanto como una potencialidad intelectual como psicología del ser humano.

${ }^{3}$ Tales elementos pueden ser el orgullo nacional o la identidad étnica.

${ }^{4}$ MacIntyre utiliza más bien el término "esencial". 
La tradición estaría presente de esta manera en teorías sociales y filosóficas, tanto clásicas como contemporáneas, como un elemento benigno en la conformación y organización de las sociedades al dar al individuo un piso existencial y vinculante con el mundo y los otros, aunque el autoritarismo y el fundamentalismo son dos características controversiales que las hacen indeseables, particularmente, en los países occidentales. Es este tipo de interpretaciones, desde el campo de la Sociología y la Antropología, las que dan fuerza el día de hoy a donde se aboga por un estudio más profundo, filosófico y social del conjunto de las tradiciones, ya no por su consideración como prácticas opuestas a la modernidad o como prácticas cosificadas o estereotipos del saber popular relacionados con el oscurantismo y el fanatismo. ${ }^{5}$

\section{Relación entre metafísica y tradición}

Ortega y Gasset, al criticar el estado lamentable de la Espańa de principios del siglo XX donde las "masas" se entregan ciegamente a la novedad tecnológica y la homogeneidad del mundo industrial, apunta la pretensión de eliminar el mundo tradicional de la vida española como si esto fuera un asunto de pura decisión política originada por una moda iconoclasta. También, al referirse en particular a los llamados doctrinarios Guizot y Royer Collard, que en el siglo XVIII defendieron ideas calificadas de conservadoras o tradicionalistas, comenta que sus ideas sobre la libertad y el progreso, a diferencia de los ilustrados, no se fundan en la novedad sino en la continuidad:

\footnotetext{
${ }^{5}$ Nestor García Clanclini, por ejemplo, tiene en claro la relación que ha existido entre folclore como tradición muerta o estática basada en puros productos sin considerar los contextos y procesos sociales que dan lugar a las tradiciones. Es una caracterización negativa del folclore y sus objetos antes que una crítica a un modo de pensar tradicional.
} 
La historia es la realidad del hombre. No tiene otra. En ella se ha llegado a ser tal como es. Negar el pasado es absurdo e ilusorio, porque "el pasado es lo natural del hombre que vuelve al galope". El pasado no esta ahí y no se ha tomado el trabajo de pasar para que lo neguemos, sino para que lo integremos.

Pasado y tradición se presentan regularmente conexos del mismo modo que la tradición y la verdad absoluta. Aún y cuando los sociólogos como Giddens señalan que la tradición se trata solamente de una práctica social que busca la vinculación comunitaria y que la mayor parte de las tradiciones en realidad no tienen un origen tan oscuro y lejano, sino que muchas de ellas surgen de una convención temporal incluso utilitaria, vemos que la tradición o las tradiciones, en particular aquellas de carácter cultural y religioso, mantienen una estrecha vinculación con una fundamentación metafísica al presentarse como depositarias de una verdad revelada y absoluta que es necesaria preservar. Tomás de Aquino, en la Edad Media, hace depositario al Maestro (Magister) de una verdad, realizador de un mensaje que se ubica más allá del tiempo humano; igualmente, Pascal en sus Pensamientos reflexiona sobre la justicia al introducir el tema de la costumbre, término que podemos identificar sin dificultad con el de tradición, si se considera dentro de la misma la autoridad y una verdad fundamental. La costumbre, ${ }^{6}$ dice Pascal, ha de ser obedecida pues así conviene al Estado, aun y cuando las leyes que de ellas se derivan son mudables, relativas en el tiempo y la historia, de tal manera que hablar de una ley o costumbre universal, única no es posible, pues si se le conociese:

${ }^{6}$ La costumbre puede ser entendida como tradición en el contexto aquí comentado, ya que se considera como el conjunto de prácticas políticas o sociales que implican una obediencia dogmática en las cuales el factor de autoridad es sobresaliente e incontestable. A diferencia de la costumbre en el sentido empirista como David Hume, que la trata como una rutina del pensamiento o bien un proceso establecido por la mente debido a la repetición. 
El resplandor de la verdadera equidad habría subyugado a todos los pueblos, y los legisladores no hubieran tomado por norma, en lugar de esta justicia constante, las fantasías de los persas y alemanes. La veríamos planteada por todos los Estados del mundo y en todos los tiempos en lugar de ver, como ahora, que casi nada de lo que se dice de lo justo y lo injusto deja de cambiar cuando se cambia de clima (Pascal, 1989: 311).

La mudanza y la relatividad son el destino del hombre que debe vivir en el Estado y sus leyes; así, también es absurdo para Pascal que en el nombre de la tradición se finquen acciones arbitrarias entre los pueblos y los hombres:

El latrocinio, el incesto, el asesinato de los hijos y de los padres; todo ha tenido su lugar entre las acciones virtuosas. ¿Hay nada más cómico que esto de que un hombre tenga derecho a matarme, porque él vive al otro lado del río, y porque un príncipe dispute con el mío, aunque yo no dispute con él? (Pascal, 1989: 312).

A fin de cuentas, el punto de vista de Pascal plantea los pasos de un dualismo entre la razón y el tiempo, donde el primer término es puesto en relación con el absoluto y lo inmutable en oposición a lo caprichoso o mudable en correspondencia con la condición humana y su búsqueda de poder y placer en el devenir histórico. Para Pascal, se ha corrompido la razón primera, la única y natural, y como consecuencia se da una pluralidad que lleva a la confusión o bien a las costumbres: "En la costumbre se funda toda la equidad, por la razón de que ella es recibida; éste es el fundamento místico de su autoridad" (Pascal, 1989: 312). Queremos subrayar aquí el término místico, el cual denota la pretensión de una fundamentación extra mundana de la costumbre. Incluso, la reflexión de Pascal deviene en una defensa del Estado en cuanto que considera a la costumbre como elemento vinculador de la sociedad en beneficio del orden. Ésta es una cuestión que toca de cerca la relación entre la tradición y la metafísica como aspecto fundacional, pues 
se deriva un orden social que es traicionado por el capricho de los violentos como justificante de sus acciones, sean como integrantes del Estado o bien como participantes y creyentes de una costumbre. En el caso de Pascal se encuentra plenamente justificado que la costumbre se ligue a la autoridad, pues ve la necesidad de mantener la justicia y el gobierno a toda costa, de ahí que sea necesario mentir a los gobernados acerca de la naturaleza convencional de la costumbre y su relatividad histórica, ya que de lo contrario ésta sería cuestionada, de nuevo. El enfoque del francés parece contradictorio al juzgar, particularmente, la arbitrariedad de la costumbre en el aspecto práctico de la autoridad, para luego poner en relieve su necesidad como coadyuvante del orden social, ya sea como una razón política o bien como una defensa del orden tradicional; ya que si los gobernados, dice Pascal, han errado en la ley natural, perfecta, absoluta, corrompiéndola en costumbres erradas es frecuente denunciar la desviación y solicitar su anulación a favor de la verdad. Sin embargo, para evitar la anarquía y la sublevación conviene mantener la costumbre como principio de autoridad pero sin que los gobernados lo descubran:

Pues no conviene que aquel sienta la verdad de tal usurpación; algunas veces ella ha sido introducida sin razón, pero se ha convertido en razonable; precisa hacerla pasar por autentica, eterna, y ocultar su comienzo, si no se quiere que bien pronto toque a su fin (Pascal, 1989: 312).

Dado que de la naturaleza primera se ha perdido el bien primero también, el hombre crea una segunda naturaleza, crea creencias que la sustentan, donde lo importante no es su verdad, dice Pascal, sino que sea respetada incluso por la acción de la fuerza. La reflexión pascaliana sobre la justicia derivada en la costumbre da pie para analizar la relación entre tradición y metafísica como algo que apunta a la afirmación del orden social sobre lo individual. El fundamento en Pascal ha devenido en la ausencia de una 
moral objetiva, perdida para el hombre, encontrada sólo en la fe, que persiste en la necesidad de una moral cualquiera; la costumbre debe valer, se nos dice, no porque contenga verdad, como afirmaba Montaigne, sino porque es costumbre. En la segunda naturaleza, la costumbre ocurre como una afirmación del principio de autoridad fundacional necesario impuesto por el hombre y operado por un principio de convención. Por lo demás, Pascal presenta una forma rara de hacer valer un sustento metafísico para el quehacer humano, especialmente en lo referido a la costumbre, que hemos de tomar como tradición, pues es necesario observar que no tiene verdad contenida en sí, sino que es una verdad derivada de un principio inalcanzable por su naturaleza extra humana. Pascal abre la puerta, por paradójico que esto resulte, a una convencionalidad rayana en el relativismo cultural al admitir que una costumbre o una tradición es falsa a fin de cuentas pero positiva y apreciada (defendida a toda costa) por sus beneficios en el orden político y moral. Incluso que puede ser adaptada ya que lo importante es que persistan las costumbres como tales. Nos encontramos con un argumento que anuncia el agotamiento metafísico y su paso a las sombras de lo inalcanzable.

A pesar de lo anterior, he de decir que existen dos puntos que no me es posible admitir presentes en la tesis de Pascal que postula una costumbre fundada como alivio convencional para una carencia de verdad fundamental y absoluta: primero, es inaceptable una mentira de Estado para mantener el orden político y social; segundo, la idea de las tradiciones como leyes o normas que deben ser defendidas incluso con la fuerza. Esto porque no se puede aceptar que las prácticas tradicionales, al proponer una convención vinculante como benéfica para el orden humano, estén dotadas de una carga de violencia que puede ser interpretada como un pretexto para la represión. Afirmaré, por tanto, la idea de la práctica 
tradicional, de origen religioso como lúdico o de otro tipo, ${ }^{7}$ como fundada en una convención, que ha de aceptarse como tal y que será apreciada por su poder para ser referente de un orden posible que es necesario perseguir y recordar constantemente con el fin de acercarse a su posible bondad y, por lo tanto, rechazar así cualquier signo de violencia o crueldad innecesaria. Me interesa destacar y afirmar que, por tanto, las prácticas tradicionales deben ser consideradas como prácticas culturales ligadas a un sentimiento religioso (aunque no de manera necesaria como acabamos de mencionar) dispuestas para estrechar vínculos sociales y cooperación entre los individuos; del mismo modo, deben reflejar una distancia del Estado o la Religión instituida para perfilarse como prácticas llenas de sentido simbólico capaces de efectuarse en contextos de convivencia pública, promoviendo tanto el vínculo social y político como actitudes de tolerancia y respeto por parte de sus practicantes. Es claro que tal desvinculación puede sonar imposible o descabellada en naciones donde Estado y Religión están profundamente unidos, pero me parece que es posible desde algunas experiencias nacionales, como la del Reino de Buthan donde se avanza hacia una modernidad donde se combina el laicismo del Estado con las prácticas tradicionales, en un intento, no sabemos aún si exitoso o no, de equilibrar tradición y modernidad ${ }^{8}$

${ }^{7}$ Puede decirse que una tradición puede establecerse como forma de un ritual o una experiencia de iniciación, protección, entre otras. Es necesario precisar que las diversas prácticas tanto en México como otros países de Latinoamerica pasan por el tamiz del Catolicismo preferentemente pero algunas salen del mismo en forma de prácticas lúdicas (oficios, juegos, competencias)

${ }^{8}$ Puedo citar aquí el artículo de la revista National Geographic (marzo del 2008, en inglés) sobre el Reino de Buthan y su política "Iluminada", pues combina aspectos económicos modernos propios de la era Global y elementos provenientes de sus tradiciones budistas. Reconocer e impulsar aspectos de estas prácticas sobre un plano social ha resultado excelente hasta ahora para contener aquellas aristas negativas que se asocian tanto a la pérdida de identidad nacional como a 
Con lo expuesto hasta aquí, podríamos resumir, aunque no en forma concluyente, que la relación de metafísica y tradición ha entrado en una clara crisis, particularmente en el Occidente (Europa, Estados Unidos y Latinoamérica), que plantea una distancia del fundamento teológico o fundamento fuerte y las prácticas tradicionales. Los intentos de algunas sociedades para resistir la embestida de un orden civilizatorio dominado por la exigencia tecnológica y la depredación ambiental, particularmente en Asia y el ámbito islámico, ${ }^{9}$ estarán condenados al fracaso mientras los sistemas políticos permanezcan anclados, por un lado, a procedimientos destructivos de las identidades y prácticas tradicionales $\mathrm{y}$, por otro, a un vínculo entre teología y política duro e intransigente donde se traiciona el espíritu de una tradición como vinculación.

Pasaré ahora a una última reflexión sobre el carácter de la tradición, donde se presenta como fundamento de verdad ya sea en el sentido teológico o bien en el convencional, para destacarlo sobre la realidad de una era de convalecencia metafísica.

\section{Conclusión: La tradición y la convalecencia ¿una forma de pensar y vivir la metafísica del rememorar?}

El mundo conceptualizado como pensamiento débil en Vattimo describe una época donde el hombre se ha olvidado del fundamento metafísico, o una ausencia de Dios, o bien la ausencia de un piso o certeza existencial para quedarnos solos frente al dominio técni-

la vinculación social en naciones subdesarrolladas que adoptan estándares occidentales de desarrollo de manera abrupta.

${ }^{9}$ Aunque en México, por ejemplo, se encuentra el caso del pueblo de Cherán en el estado de Michoacán, donde a semejanza de Buthan se hurga tanto en la herencia tradicional como en los elementos políticos, económicos, sociales y culturales para hacer frente a una economía liberal que destruye vínculos sociales e identidades culturales. Los casos pueden ser numerosos en el resto de América Latina, incluso África. 
co; del mismo modo, una era de crisis de la representación del Ser para entrar en la experimentación del mismo como fundamento o presencia débil. Junto a esta crisis tenemos también un retorno de la religión que ha resultado, dice el filósofo turinés, del desencanto del desencanto de las corrientes positivistas del siglo XX, lo cual permite hablar de un retorno o bien una vuelta a la experiencia religiosa desde un particular punto de vista que considera la impronta de la experiencia de la modernidad. Hablar de metafísica o de religiosidad en el marco del pensamiento débil implica pensar de nuevo la presencia desde la diferencia, de la desacralización de Dios, pero considerando su rastro como un "ruido de fondo" en la existencia y el devenir.

Relacionar la tradición con la metafísica y la teología resulta con frecuencia algo obvio, pero esta relación no es tan evidente en sus fundamentos como lo es a partir de prácticas rituales o símbolos; muchas de las tradiciones o las prácticas tradicionales, al menos en la realidad europea y latinoamericana, contienen una importante presencia de elementos provenientes del cristianismo. La conexión entre dogmas y prácticas católicas es evidente, puesto que en la tradición filosófica, valga la redundancia, se encuentra tratado el asunto de la práctica tradicional como un aspecto derivado de la observación de los cultos y rituales, incluso como sinónimo de estos últimos. De esta manera, Para du Phanjas, sacerdote jesuita, en pleno siglo XVIII define la tradición como el habla de las generaciones que contienen una verdad revelada no escrita, que se sostiene en la sucesión de las generaciones (Phanjas, 1767). Si el pensamiento débil de Vattimo se refiere a una forma de convalecer la metafísica -sea como añoranza, diálogo abierto o retorno secularizado-, este aspecto particular llamado tradición puede revelarnos una dimensión de esta convalecencia que hace falta explorar, especialmente en el mundo tradicional, donde la sucesión de generaciones es un fundamento en sí mismo de una 
verdad o bien un acercamiento a una verdad. Pero no solamente la cuestión del fundamento debilitado y la verdad agotan el mundo tradicional, hace falta poner también en cuestión su posibilidad como un elemento antropológico que define la humanidad por su capacidad de crear nuevas realidades a partir de lo acumulado en la memoria, pues tal y como lo plantea Scheler, el animal sobrevive gracias a la "tradición" esto es, a un comportamiento de manada que es transmitido de generación en generación, mientras que en el ser humano la auténtica evolución radica en su capacidad de revolucionar y romper con la tradición (Scheler, 1981: 44). Desde mi punto de vista, la reflexión de Scheler es cierta hasta donde señala que debemos remontar todo contenido tradicional en aras de un progreso significativo como especie, aunque se refiere a la tradición como conducta memorizada y no precisamente a la cultura. Es necesario observar que aún y cuando las tradiciones son, como el mismo Scheler señala, "sugerentes" más que objetivas y por ello dispuestas para la reinterpretación y el rompimiento, después de tal rompimiento se crearán otras pautas de conducta (o bien contenidos culturales) que serán considerados tradicionales nuevamente.

Scheler remata su reflexión sobre la tradición estableciendo que la misma ha de hacerse a un lado para dejar paso a la invención y el progreso (1981:45), afirmación que es pertinente acotar por lo que acabamos de mencionar, es decir: el progreso deja atrás la tradición, pero sólo para convertirse nuevamente en tradición. Por lo tanto, es una relación que no es posible negar y aunque Scheler no lo hace favorece sin lugar a dudas el papel de la Ratio progresiva en el hombre y, al parecer, la paulatina desaparición de la dimensión tradicional del ser humano así como sus expresiones culturales. Por otra parte, Mario Teodoro Ramírez establece su posición sobre el tema donde sostiene que la tradición posee una dimensión consistente en hacer presente el pasado, lo cual constituye un 
tiempo propio de la tradición, mismo que posibilita toda práctica tradicional. En el panorama de una modernidad encaminada en la técnica, la tradición, dice Ramírez, es posibilidad abierta antes que cerrazón, dado que dichas prácticas tradicionales son antes que nada realización, diálogo y capacidad de formación de conceptos. Igualmente, nos recuerda este mismo autor, la tradición no es pasividad sino crítica, pues al efectuarse una toma de posición sobre el mundo se hace ya desde una posición determinada precisamente por la herencia, esto es, desde una tradición o práctica tradicional (2003: 103-104).

La interpretación de Pablo Lazo (2008: 60- 64), por último, sobre la hermenéutica de Charles Taylor, acunada desde la herencia de Herder y Hegel, destaca la preeminencia que otorga a la genética histórica del sujeto y sus acciones para ponerlas en juego en la interpretación del otro o los otros, en un diálogo en el cual ambos, interpretante e interpretado se modifican mutuamente, dándose el encuentro entre sujetos de distintas culturas o entre las culturas que se narran a sí mismas pero con una influencia recíproca. La propuesta tayloriana, subraya Lazo, se orienta a la conformación de un camino que se aparta tanto de las explicaciones basadas en el atomismo individualista del liberalismo como de las visiones colectivistas holistas. Lo productivo que podemos apreciar en esta interpretación para el problema de la tradición es la posibilidad de la misma como una construcción abierta, tanto a la autoconformación o la autonarración como a la asimilación de las influencias del otro. Modificación, se admite, que nunca agota lo que ambos involucrados en el proceso de interpretación son, pues siempre queda algo como inexplicable. El punto que ha destacado Lazo es relevante para la comprensión del mundo tradicional mexicano donde la autonarración de un grupo étnico por medio de sus ex- 
presiones tradicionales hace acopio de elementos políticos o económicos coyunturales o de gran impacto simbólico. ${ }^{10}$

Tanto Lazo como Ramírez son partidarios de una visión constructiva de las prácticas tradicionales o bien de la tradición considerada como dimensión humana omnipresente, donde se presenta como un espacio y un tiempo de producción creativa así como de expresiones críticas frente a los poderes políticos, los poderes mercantiles y la avance tecnológico deshumanizante e impersonal de la globalización; sin embargo, aunque mi punto de vista coincide con algunos con los autores citados, debo hacer notar que uno de los problemas irresueltos sobre la tradición es su evidente confrontación con los modos de vida democráticos que exigen que toda práctica tradicional sea respetuosa de los derechos humanos y el medio ambiente (incluidos los derechos animales), problema al cual tiene que darse una respuesta convincente, acorde a la sensibilidad de nuestros tiempos. Un caso claro tanto en Latinoamérica como en Espańa, son las corridas de Toros, donde los reclamos contra una fiesta tradicional (aunque mercantilizada, mitad tradición, mitad espectáculo) alcanzan grados de clamor masivo. Es ante tales elementos que los pueblos alrededor del planeta tienen que abogar para conciliar ese espacio de creatividad, memoria e identidad que es la práctica tradicional con las exigencias de orden político y social cada vez más universal, orientado hacia los valores acuñados en la democracia liberal, salvo, claro está, aquellas partes del mundo que se rigen por otros valores.

De esta manera, he tratado de explorar aquí lo que la tradición nos presenta como problemático en el contexto del pensamiento

${ }^{10}$ Es el caso por ejemplo de las danzas de matachines en el norte del país o la quema de Judas en casi todo el territorio nacional, donde los políticos son blanco de las burlas y escarnios plasmados en representaciones grotescas. 
débil ${ }^{11}$ con la inclusión de las reflexiones sobre la tradición, en el sentido del rescate de sus capacidades como conjunto de prácticas vinculantes o creativas que reciben atención dentro de varias propuestas filosóficas; aunque queda pendiente de desarrollar en forma más amplia. Puede entreverse, sin embargo, que nos aproximamos a la difícil relación entre el particular modo de sentir y pensar del mundo tradicional y una realidad social y política (la nuestra principalmente, en los inicios del siglo XXI) que se caracteriza por el ataque a los fundamentos metafísicos y toda representación que no cuadre en los controles de mercado o cálculo del capitalismo global; época, la nuestra, que ha trabajado con ahínco tanto en la destrucción de formas de vida tradicional ${ }^{12}$ como contra los ímpetus nacionalistas y religiosos que sobreviven en el planeta pero que, al mismo tiempo, no ha ofrecido modos de vida que reemplacen, al menos para una gran mayoría, los modos de vida tradicionales y sus prácticas vinculantes. Por supuesto, tendríamos que considerar los países desarrollados, en particular Europa, donde tal vez se ha avanzado en tal sentido y se ha rescatado lo vital y creativo de las prácticas tradicionales en un marco democrático y laico, pero eso sería un asunto por estudiar.

${ }^{11}$ Queda por comentar también el carácter que Heidegger otorga al lenguaje tradicional como lugar de lo no dicho o no manifestado, que se resiste al puro informar de la era técnica, propio en el habla natural o tradicional, esperando para decir el mundo nuevamente. Lo anterior como complemento al pensamiento débil de Vattimo. Ver la conferencia de Heidegger "lenguaje técnico y lenguaje tradicional” de 1962, de la cual existe una versión en línea en la dirección: https://ucursosadi.ing.uchile.cl/filosofia/2010/2/386100820/1/material_docente/previsualizar?id_material=472370

${ }^{12}$ Me refiero principalmente a los sucesos en Latinoamérica, donde las sociedades originarias de América han visto amenazadas sus identidades por un entorno hostil hacia sus costumbres y prácticas tradicionales, en el marco de una depredación de regiones y territorios considerados imprescindibles para tales comunidades tanto en sentido simbólico como económico (ej. los Yanomami del Amazonas o los Lacandones de México). 
Igualmente, debemos considerar que nuestras reflexiones deben estudiar cómo lo tradicional y las tradiciones en general, que estamos lejos de considerar benéficas en sus aspectos más violentos o despóticos, nos llaman hacia la vinculación y la solidaridad. Incluso, diremos por último, que la tradición puede ser simulacro y parodia en el sentido dado por el pensamiento de la diferencia derrideano (Vattimo, 1999: 136) condición que Vattimo señala como indeseable para toda aquella práctica que actúe o pretenda estar edificada sobre fundamentos metafísicos o trascedentes, como lo son en su mayoría las prácticas tradicionales. Se trataría, agregamos con el italiano, de una práctica o conjunto de prácticas que coadyuven a una ética de la no violencia, de ninguna manera a la opresión de comunidades y personas, el ámbito de la tradición como esfera propia de un hacer cultural humano ha de distinguirse de un ámbito de utilidad y mero conformismo con la mercadotecnia, puesto que si las prácticas tradicionales están condenadas a desaparecer debemos considerar que esa forma de ser del humano persistirá en hacer valer sus principales aportaciones: memoria y vitalidad.

\section{Bibliografía}

Berciano, Modesto, 1993, Heidegger, Vattimo y la Deconstrucción, España, Anuario Filosófico de la Universidad de Navarra.

Goméz-Limón, Ma. Teresa e Isabel González, 2011, Las tradiciones que no aman a las mujeres, España, Akal/FOCA.

Lazo, Pablo et al, 2008, Memoria instituida, memoria instituyente, México, UIA.

MacIntyre, Alasdair, 2001, Tras la Virtud, Barcelona, Crítica.

Pascal, Blas, 1989, Pensamientos, México, Porrúa. 
Phanjas, Para, 1767, Metaphysque Sacreé et Profane, ou theorie de étres insensibles, Francia, Jombert Pere/Librerie du Roi, edición electrónica, disponible en: www.Gallica.bnf.fr

Ramírez, Mario Teodoro, 2003, De la razón a la praxis, México, UMSNH/Siglo XXI.

Scheler, Max, 1981, El puesto del Hombre en el Cosmos, Argentina, Losada.

Vattimo, Giani, 1896, Fin de la Modernidad, México, Gedisa. , 1996, Creer que se cree, España, Paidós. , 1999, Las aventuras de la diferencia, España, Altaya.

(Recibido: 9 de agosto de 2015, aceptado: 2 de noviembre 2015) 